AperTO - Archivio Istituzionale Open Access dell'Università di Torino

\title{
Oral administration of tepoxalin in the horse: A PK/PD study
}

\section{This is the author's manuscript}

Original Citation:

Availability:

This version is available http://hdl.handle.net/2318/80291

since 2016-01-13T15:57:57Z

Published version:

DOI:10.1016/j.tvjl.2010.09.013

Terms of use:

Open Access

Anyone can freely access the full text of works made available as "Open Access". Works made available under a Creative Commons license can be used according to the terms and conditions of said license. Use of all other works requires consent of the right holder (author or publisher) if not exempted from copyright protection by the applicable law. 


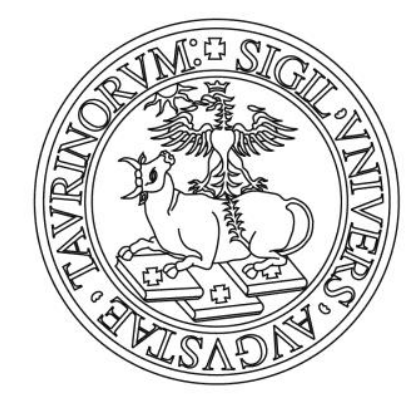

\section{UNIVERSITÀ DEGLI STUDI DI TORINO}

This Accepted Author Manuscript (AAM) is copyrighted and published by Elsevier. It is posted here by agreement between Elsevier and the University of Turin. Changes resulting from the publishing process - such as editing, corrections, structural formatting, and other quality control mechanisms - may not be reflected in this version of the text. The definitive version of the text was subsequently published in The Veterinary journal, 190, 1, 2011, doi 10.1016/j.tvj1.2010.09.013

You may download, copy and otherwise use the AAM for non-commercial purposes provided that your license is limited by the following restrictions:

(1) You may use this AAM for non-commercial purposes only under the terms of the CC-BY-NC-ND license.

(2) The integrity of the work and identification of the author, copyright owner, and publisher must be preserved in any copy.

(3) You must attribute this AAM in the following format: Creative Commons BY-NC-ND license (http://creativecommons.org/licenses/by-nc-nd/4.0/deed.en),

doi 10.1016/j.tvj1.2010.09.013 
Oral administration of tepoxalin in the horse: A PK/PD study

Mario Giorgi a,, Barbara Cuniberti b, Guisheng Ye c, Raffaella Barbero b, Micaela Sgorbini ${ }^{a}$, Cristina Vercelli ${ }^{b}$, Michele Corazza ${ }^{a}$, Giovanni Re ${ }^{b}$

a Department of Veterinary Clinics, University of Pisa, Via Livornese (lato monte) 1, 56010 S Piero a Grado, Pisa, Italy

${ }^{b}$ Department of Animal Pathology, Div. of Pharmacology \& Toxicology, University of Turin, Via L. da Vinci 44, 10095 Grugliasco, Torino, Italy

c Department of Veterinary Medicine, College of Agriculture and Animal Husbandry, Qinghai University, Xining, China

\section{ABSTRACT}

Tepoxalin is a non-steroidal anti-inflammatory drug with analgesic, anti-inflammatory, and antipyretic properties and has been recently introduced into veterinary medicine. The aim of this study was to evaluate the pharmacokinetic/pharmacodynamic (PK/PD) profile of tepoxalin to assess whether it would be suitable for clinical use in horses. Six female fasting/fed horses were given $10 \mathrm{mg} / \mathrm{kg}$ tepoxalin orally in a cross-over study. After administration, tepoxalin underwent rapid and extensive hydrolytic conversion to its carboxylic acid metabolite RWJ-20142. In animals that had been fed, the plasma concentrations of tepoxalin were undetectable, whereas in fasting animals they were close to the limit of quantification of the method. No differences between the fasting/fed groups in RWJ-20142 plasma concentrations were shown. Tepoxalin showed a strong and longlasting ex vivo inhibitory activity against cyclooxygenase (COX)-1, mainly due to its main metabolite RWJ-20142. Tepoxalin and RWJ-20142 do not seem to possess either COX-2 or 5-lipoxygenase inhibitory activity in the horse. These features suggest that the drug is a selective COX-1 inhibitor in horses, with no significant anti-inflammatory activity. Thus, its long term use in equine practice could be of concern.

Keywords: Tepoxalin, RWJ-20142, Horse, Pharmacokinetics, Pharmacodynamics, PK/PD

\section{INTRODUCTION}

Chronic inflammatory diseases, such as osteoarthritis, are among the most common causes of reduced function in animals, especially horses (Richardson and Loinaz, 2007). Inflammation,pain, joint alteration/deformation, and impaired locomotion with variable (but usually worsening) degrees of incapacitation are common symptoms. The main aim of current therapeutic strategies is to alleviate the symptoms, particularly those of pain and inflammation. The most commonly used remedies are non-steroidal anti-inflammatory 
drugs (NSAIDs) (Goodrich and Nixon, 2006). However, NSAIDs can cause serious adverse effects, the most important of which are gastric lesions (e.g. ulceration), renal failure, and asthma (Lascelles et al., 2005). Both the adverse and therapeutic effects of NSAIDs are primarily the result of the inhibition of the activity of prostaglandin (PG) endoperoxide synthase, or cyclooxygenase (COX) (Brooks and Day,1991). Inhibition of the constitutively expressed COX-1 isoform causes gastric and intestinal mucosal damage and renal toxicity,

whereas inhibition of the inflammatory-induced COX-2 isoform reduces inflammation. Arachidonic acid not metabolised to prostaglandins by the COX enzymes may enter into the lipoxygenase (LO) pathway, increasing the formation of leukotrienes (LTs) and cysteinyl-LT (Rainsford, 1987, 1993). This causes vasoconstriction at the level of gastric mucosa and increases the formation of reactive oxygen radicals from the peroxidative cleavage of hydroxyeicosatetraenoic acids (Los et al., 1995), resulting in further mucosal injury. The gastric and intestinal mucosal lesions produced by NSAIDs can be prevented by the concurrent administration of 5-LO inhibitors (Rainsford, 1987, 1993). 5-LO converts free arachidonic acid to the unstable intermediate 5-S-hydroperoxyeicosatetraenoic acid (5-HPETE), that is subsequently converted to LTA4, the 5,6 epoxide of arachidonic acid, which is also unstable (Goldyne, 1984; Stenson and Parker, 1984; Higgs and Moncada, 1985). Depending on the constituent enzymes, LTA4 is then converted to a variety of LT derivatives, including LTB4 a potent chemotactic agent associated with inflammation that recruits, activates, and prolongs the actions of neutrophils and other inflammatory cells upregulating the cytokine production (Crooks and Stockley, 1998; Bertolini et al., 2001). Tepoxalin, 5(4-chlorophenyl)-N-hydroxy-(4-methoxyphenyl)-N-methyl-1H-pyrazole-3propanamide (Fig. 1), is a NSAID with analgesic, anti-inflammatory, and antipyretic properties that has recently been marketed for use in veterinary medicine. Tepoxalin has been approved for use in dogs by the European Committee for Medicinal Products for Veterinary Use (Zubrin, Schering-Plough) (Zubrin, EPARs/02/10/08). Due to its ability to inhibit both COX isoforms and 5-LO, it is considered a dual inhibitor (Wallace et al., 1993). By reducing the production of LTB4, tepoxalin might offer a novel approach to both the preservation of Gl mucosal integrity and reduction of bronchoconstriction (Wallace et al., 1993; Bertolini et al., 2001; Lees, 2009). Tepoxalin is supplied as a rapidly disintegrating tablet that completely dissolves within a few seconds in the animal's mouth (Anonymous, 2003). Studies conducted in rats (Knight et al., 1996), chickens (De Boever et al., 2009), rabbits (Pollock et al., 2008), dogs (Knight et al., 1996; Homer et al., 2005) and humans 
(Waldman et al., 1996) reported that the parent compound reached maximum plasma concentrations in a variable time (0.7-4 h), and was rapidly converted to the active metabolite RWJ-20142. The dual activity of tepoxalin and the potent COX-1 activity inhibition of its metabolite have been demonstrated in different studies (Argentieri et al., 1994; Willburger et al., 1998; Goodman et al., 2009), and the long plasma half-life of the active metabolite allows once-a-day dosing (Homer et al., 2005). According to Waldman et al. (1996), only tepoxalin (and not RWJ-20142) contributes to 5-LO inhibition. However, Willburger et al. (1998) demonstrated that in human blood, although a low plasma concentration of tepoxalin can inhibit COX enzymes, the same concentration did not affect 5-LO inhibition. Agnello et al. (2005) showed that in dogs administration of $10 \mathrm{mg} / \mathrm{kg}$ of tepoxalin once daily for 10 days significantly reduced PGE2 production but not LTB4. In the dog, tepoxalin has been shown to be effective and safe in its therapeutic range (Goodman et al., 2009) after single (Homer et al., 2005) and repeated (Knight et al., 1996) administrations. Tepoxalin has been experimentally used in chickens at high dosages (30 $\mathrm{mg} / \mathrm{kg}$ ) with no adverse effects reported (De Boever et al., 2009). Several differences have been reported in pharmacokinetic (PK) parameters between species (Waldman et al., 1996; Homer et al., 2005; Pollock et al., 2008; De Boever et al., 2009), so species-specific data are required. In the horse, there has been just one published study (Caruso et al., 2009). This was a brief in vitro study which reported only the pharmacodynamic properties (PD) of tepoxalin, while data concerning the dynamics of RWJ-20142 were missing. In vitro analyses of PD need to be paired with PK data to predict the clinical response, as the latter influences the concentration of the active molecule within tissues. In fact COX selectivity generally decreases when in vivo assays are compared to in vitro results (Bertolini et al., 2001). This study was undertaken to assess whether tepoxalin has suitable clinical features in horses, by the evaluation of its PK/PD profile using an equine whole blood assay.

\section{MATERIALS AND METHODS}

The study protocol was approved by the Ethics Committee of the University of Pisa (authorization 9403) and transmitted to the Italian Ministry of Health.

\section{Animals and experimental design}

Six female horses, aged 7-12 years and weighing 450-550 kg, were used. The mares were considered clinically healthy on the basis of a physical examination and complete 
haematological analyses. Animals were randomly assigned to two treatment groups, using an open, single-dose, two treatment, two-period, cross-over design. Each subject received a single dose of $10 \mathrm{mg} / \mathrm{kg}$ tepoxalin using Zubrin $200 \mathrm{mg}$ tablets (Schering-Plough), bought in an ordinary pharmacy. The first group $(n=3)$ received the treatment in the morning, after fasting for $12 \mathrm{~h}$ overnight up to $6 \mathrm{~h}$ after drug administration. The second group ( $\mathrm{n}=3$ ) was treated in the morning $2 \mathrm{~h}$ after feeding. After a wash-out period of 2 weeks the groups were reversed and the treatments repeated. Since no information was available for horses a long wash-out period was chosen. This not only guaranteed the absence of residual plasma concentrations of the drug and its metabolite, but also the lack of residual drug effect on clearance (induction/inhibition) (Toutain and Bousquet-Mélou, 2004). The animals that were fed were provided with a diet composed of a mixture of ground cereals (Equifioc, Molitoria Val di Serchio) in the afternoon (1.5 kg/day) and alfalfa hay in the morning $(8 \mathrm{~kg} /$ day). Fasting horses were given hay only $6 \mathrm{~h}$ after drug administration. All of the animals were given the oral lyophilised formulation dissolved in $100 \mathrm{~mL}$ of distilled water via nasogastric tube. After administration, the nasogastric tube was rinsed with $1 \mathrm{~L}$ of distilled water to ensure complete delivery of the drug into the stomach. Objective symptoms such as sweating, excitement, trembling, and head nodding were scored using numerical rating scales (Derksen et al., 1999). Vital signs including blood pressure, heart rate, respiratory rate and body temperature were assessed during the study. A catheter was placed into the right jugular vein to facilitate blood sampling.

Blood samples for PK analysis $(10 \mathrm{~mL})$ were collected at intervals of $0,5,15,30$, and 45 min, and 1, 1.5, 2, 4, 6, 8, 10, 24, 34, 48, 58 and $72 \mathrm{~h}$ after tepoxalin administration, and placed in collection tubes containing lithium heparin. The blood samples were centrifuged at $400 \mathrm{~g}$ for 5 min within $30 \mathrm{~min}$ of collection, and the harvested plasma was stored at -20 ${ }^{\circ} \mathrm{C}$ and was used within 14 days from collection. Blood samples for PD analysis were collected at $0,2,10,24,48$ and $72 \mathrm{~h}$ after drug administration $(n=3)$. Blood for the COX1, COX-2 and 5-LO activities measurement was collected into siliconised glass, sodiumheparinised and lithium-heparinised tubes (Venoject, Terumo), respectively.

\section{Preparation of samples for $P D$ analysis}

Aliquots of non-heparinised blood $(10 \mathrm{~mL})$ were incubated at $37{ }^{\circ} \mathrm{C}$ for $1 \mathrm{~h}$ to allow thromboxane (TX)B2 production from platelets. Tubes were centrifuged at $400 \mathrm{~g}$ for $10 \mathrm{~min}$ at room temperature and the serum was stored at $-20{ }^{\circ} \mathrm{C}$. Aliquots $(2 \mathrm{~mL})$ of sodium- 
heparinised blood were transferred into glass tubes containing a final concentration of 10 $\mathrm{lg} / \mathrm{mL}$ lipopolysaccharide (LPS) from Escherichia coli (serotype 0111:B4) (Sigma) in phosphate buffered saline (PBS) solution and incubated at $37^{\circ} \mathrm{C}$ for $24 \mathrm{~h}$ to simulate PGE2 production from mononuclear cells. Blood with PBS only was used as a negative control. At the end of the incubation period, blood was centrifuged at $400 \mathrm{~g}$ for $10 \mathrm{~min}$ at room temperature to obtain plasma. A $100 \mu \mathrm{L}$ aliquot of plasma was mixed with $400 \mu \mathrm{L}$ of HPLC-grade methanol (Carlo Erba) to precipitate proteins. The mixture was centrifuged at $400 \mathrm{~g}$ for $10 \mathrm{~min}$ at room temperature; the supernatant was collected and stored at $-20^{\circ} \mathrm{C}$. Aliquots $(0.5 \mathrm{~mL})$ of lithium-heparinised blood were transferred into glass tubes, containing $60 \mu \mathrm{M}$ calcium ionophore A23187 (Sigma) in DMSO, to stimulate LTB4 production from neutrophils. Blood with DMSO only was used as the negative control. Tubes were incubated at $37{ }^{\circ} \mathrm{C}$ for $30 \mathrm{~min}$. Two millilitres of methanol were added to the mixture to precipitate proteins, and the tubes were immediately immersed in ice to stop the incubation. Tubes were centrifuged at $4000 \mathrm{~g}$ for $15 \mathrm{~min}$ at $4{ }^{\circ} \mathrm{C}$ and aliquots of the resulting supernatant were stored at $-20{ }^{\circ} \mathrm{C}$ until used. TXB2, PGE2 and LTB4 were assayed using a commercial EIA kit (Assay Designs), in samples diluted 15-, 25- and 10fold, respectively, using the assay buffer supplied with the kit.

\section{Chromatographic assay}

High performance liquid chromatography (HPLC) was performed with a PU 980 isocratic pump (Jasco) attached to an AS-1550 autosampler (Jasco) and an 821-FP fluorimetric detector (Jasco). Integration was performed using Borwin chromatographic software (version 1.21). The compounds were separated on a C18 column $(250 \mathrm{~mm} \times 4.6 \mathrm{~mm}$ i.d., $5 \mu \mathrm{m}$ particles) (Gemini) with a mobile phase A, consisting of $0.01 \mathrm{M}$ 1-octane-sulfonic acid (Sigma) in $0.01 \mathrm{M}$ acetic acid (Sigma) in HPLCgrade water (Baker), and a mobile phase $\mathrm{B}$ consisting of tetrahydrofuran (Carlo Erba), mixed at 50/50 (v/v). The flow rate of the mobile phase was maintained at $1.0 \mathrm{~mL} / \mathrm{min}$. Injection volume was $50 \mu \mathrm{L}$ and the detector wavelengths were set at $290 \mathrm{~nm}$ and $440 \mathrm{~nm}$ as excitation and emission, respectively (Giorgi et al., 2011). Briefly, the quantification of tepoxalin and RWJ-20142 in plasma samples was accomplished by chromatographic analysis of unknown samples in parallel with standard curve and quality control samples created using tepoxalin, RWJ20142 and RWJ-20294 (internal standard) pure standard powders (TopChem Laboratories). For each series of analyses, a standard curve was generated as well as 
nine quality control samples (three different concentrations) alongside the test samples. The limits of detection (LOD) and quantification (LOQ) were determined as analyte concentrations giving signal-to-noise ratios of 3 and 10 , respectively.

Preparation of samples for PK analysis

The drug was extracted from horse plasma by the following procedure. The plasma sample $(0.5 \mathrm{~mL})$ was spiked with $10 \mu \mathrm{g} / \mathrm{mL}$ RWJ-20294 as an internal standard $(100 \mu \mathrm{L})$ in a $2 \mathrm{~mL}$ plastic Eppendorf tube. The mixture was vortexed for $30 \mathrm{~s}$ and left to rest for $5 \mathrm{~min}$. Acetonitrile $(0.9 \mathrm{~mL})$ (Carlo Erba) was added to the mixture as an extraction solvent. This mixture was vortexed, shaken for $10 \mathrm{~min}$ at 150 oscillation/min on a shaker, and then centrifuged at $5000 \mathrm{~g}$ at $4{ }^{\circ} \mathrm{C}$ for $15 \mathrm{~min}$. Four hundred microlitres of the upper layer were transferred to a clean Eppendorf and centrifuged again for $15 \mathrm{~min}$ at $5000 \mathrm{~g}$ at $4{ }^{\circ} \mathrm{C}$. Two hundred microlitres were separated in a $500 \mu \mathrm{L}$ Eppendorf. The aqueous phase $(50 \mu \mathrm{L})$ was then injected onto the HPLC system.

\section{PK evaluation}

The pharmacokinetic calculations were carried out using WinNonLin v 5.2.1 (Pharsight Corp). Maximum concentration (Cmax) of tepoxalin and RWJ-20142 in plasma, and the time required to reach $C \max (\operatorname{Tmax})$ were predicted from the data. The terminal rate constant $(\lambda)$ was determined from the slope of the terminal phase of the plasma concentration curve that included a minimum of three points. The half-life of the terminal phase $(T 1 / 2 \lambda z)$ was calculated by the formula $T 1 / 2=0.693 / \lambda$. The area under the concentration/time curve ( $A \cup C_{\text {last }}$ ) was calculated using the linear trapezoidal rule. Changes in plasma concentrations of tepoxalin and RWJ-20142 were evaluated using the standard non-compartmental analysis, and the relative pharmacokinetic parameters were determined using standard non-compartmental equations (Gabrielsson and Weiner, 2002).

\section{Statistical analysis}

Normal distribution of data was assessed by the D'Agostino and Pearson omnibus normality test. Consequently, the differences between the pharmacokinetics of tepoxalin during the two periods of administration, as well as the effect on prostanoid levels and 
percentage inhibition of prostanoid production were calculated using a repeat measures ANOVA, followed by the Newman-Keuls multiple comparison test. The effect of fasting/feeding status on the results was assessed using the twoway ANOVA with the Bonferroni correction as a post hoc test. A cut-off value of $20 \%$ inhibition of COX-1 was taken as the percentage value above which there may be a risk of adverse effects, and a cut-off value of $80 \%$ inhibition of both COX-2 and 5-LO was taken as the percentage value above which a good therapeutic effect would be expected (Giraudel et al., 2005). The results are reported as mean values $( \pm S E M)$. All the analyses were conducted using GraphPad InStat v.4.0 (GraphPad Software). In all the experiments, differences were considered significant if the associated $P$ value was $<0.05$.

\section{RESULTS}

Throughout the study no abnormality ascribable to the drug under study was observed as assessed by the measurement of objective symptoms, vital signs, physical examination and laboratory analysis.

\section{PK analysis}

The analytical method had a LOQ of tepoxalin and RWJ-20142 of $25 \mathrm{ng} / \mathrm{mL}$ and $20 \mathrm{ng} / \mathrm{mL}$, respectively. The maximum value of the $\mathrm{CV}$ in intra-/inter-day assay precision for tepoxalin and metabolite was 5.5\%. The plasma concentration vs. time curves for tepoxalin and RWJ-20142 were best fitted to a non-compartmental model. In fasting animals, the plasma profile of tepoxalin showed lower concentrations (Fig. 2). The Cmax $(96.8 \pm 55.0 \mathrm{ng} / \mathrm{mL}$ ) was reached in a short time ( $T \max 1.5 \pm 0.2 \mathrm{~h}$ ) and the drug rapidly disappeared from the blood compartment ( $T 1 / 2 \lambda z 2.78 \pm 0.99 \mathrm{~h}$ ) (Table 1). One of the six horses had all plasma concentrations below the $L O Q$, and another had only two collection points that were above this level. A wide variation in plasma concentrations among the subjects was observed. The metabolite RWJ-20142 showed a higher Cmax (1250 $\pm 187.4 \mathrm{ng} / \mathrm{mL})$, a longer Tmax $(9.6 \pm 0.4 \mathrm{~h})$ and a longer $\mathrm{T} 1 / 2 \lambda z(6.3 \pm 0.1 \mathrm{~h})$, than the parental compound. In the plasma of fed animals, tepoxalin concentration did not exceed the LOQ of $25 \mathrm{ng} / \mathrm{mL}$ in any horse at any time point. In this experimental group, the T1/2 $\lambda z$ of RWJ-20142 was significantly $(P=0.03)$ higher $(8.8 \pm 1.0 \mathrm{~h})$ than in fasting animals $(6.3 \pm 0.1 \mathrm{~h})$, but the pharmacokinetic profile of RWJ-20142 (Fig. 2) and the other parameters were not 
significantly different between the two groups (Table 1). In both treatments, RWJ-20142 showed a biphasic mode of formation: a first rapid phase (1.5-2 h), and a second slower phase culminating with the Tmax ( $7.7 \mathrm{~h}$ fed group; $9.6 \mathrm{~h}$ fasting group). The single curves calculated for each animal showed the same trend (data not shown). The end of the first phase coincided with the Tmax of the parental drug in fasting horses.

\section{$P D$ analysis}

In fasting and fed horses, induced TXB2 concentrations were $256.3 \pm 117.5 \mathrm{ng} / \mathrm{mL}$ and $83.9 \pm 22.1 \mathrm{ng} / \mathrm{mL}$, respectively; background PGE2 concentrations were $0.4 \pm 0.1 \mathrm{ng} / \mathrm{mL}$ and $0.7 \pm 0.2 \mathrm{ng} / \mathrm{mL}$, respectively; induced PGE2 concentrations were $0.7 \pm 0.1 \mathrm{ng} / \mathrm{mL}$ and $2.4 \pm 0.4 \mathrm{ng} / \mathrm{mL}$, respectively; background LTB4 concentrations were $0.1 \pm 0.0 \mathrm{ng} / \mathrm{mL}$ and $0.1 \pm 0.0 \mathrm{ng} / \mathrm{mL}$, respectively; induced LTB4 concentrations were $3.6 \pm 0.3 \mathrm{ng} / \mathrm{mL}$ and 3.1 $\pm 0.6 \mathrm{ng} / \mathrm{mL}$, respectively. Administration of tepoxalin at $10 \mathrm{mg} / \mathrm{kg}$ significantly decreased TXB2 concentrations at all experimental time points in both fasting $(0 \mathrm{~h}$ vs. $48 \mathrm{~h}, \mathrm{P}<0.05$ and $0 \mathrm{~h}$ vs. all other times, $\mathrm{P}<0.01)$ and fed $(\mathrm{P}<0.001)$ horses compared with the basal values. The maximal inhibition of serum TXB2 occurred at $24 \mathrm{~h}$ and was maintained for up to $72 \mathrm{~h}$ after administration (Figs. 3a and 4a). At this time point, serum TXB2 activity was still inhibited by $90.4 \pm 4.3 \%$ and $85.8 \pm 1.1 \%$ in fasting and fed animals, respectively (Table 2). Although a reduction in concentrations of PGE2 was found, this parameter did not decrease significantly within $48 \mathrm{~h}$ of drug administration $(P>0.05)$. It reached its maximal inhibition at $10 \mathrm{~h}$ (Table 2), both in fasting and fed horses. The inhibition time corresponded to the Cmax of RWJ-20142. PGE2 levels reverted back to the stimulated basal values within $72 \mathrm{~h}$ of tepoxalin administration, (Figs. $3 \mathrm{~b}$ and $4 \mathrm{~b}$ ). The concentration of LTB4 was significantly increased by stimulation with calcium ionophore $(P<0.001$ and $P<0.01$ in fasting and fed animals, respectively). In both fasting and fed horses, tepoxalin decreased LTB4 concentrations $2 \mathrm{~h}$ after administration, along with the Cmax of tepoxalin, even if the values were not statistically significant $(P>0.05)$. At all other times, LTB4 concentrations were similar to the stimulated basal values (Figs. 3c and $4 \mathrm{c}$ ). Maximum inhibition of COX-1 (99.7 $\pm 0.1 \%$ and $99.6 \pm 0.1 \%$ in fasting and fed horses, respectively) exceeded the cut-off value of $20 \%$, whereas the maximum percentage inhibition of both COX-2 (68.9 $\pm 26.6 \%$ and $65.1 \pm 8.0 \%$ in fasting and fed horses, respectively) and 5-LO (37.5 $\pm 2.9 \%$ and $43.4 \pm 4.7 \%$ in fasting and fed horses, respectively) did not exceed the cut-off value of $80 \%$ (Table 2). Fasting/feeding status significantly affected PGE2 
concentration, accounting for $29.43 \%$ of the total variance in PGE2 concentration ( $P=$ 0.0002 ). In contrast, it only accounted for $2.93 \%$ and $0.83 \%$ of the total variance of TXB2 and LTB4 values $(P=0.11$ and $P=0.38$, respectively) (Fig. 5a-C).

\section{DISCUSSION}

Several variations in PK/PD of NSAIDs among animal species have been reported (Lees et al., 2004a,b). Drugs with selective enzyme-inhibiting features in one species may have nonspecific activity in others. A PK/PD study in the target species is therefore essential for predicting the likely effectiveness and safety of the therapy. In this study PD analysis was carried out using whole blood assays, which tested TXB2 production during clotting, PGE2 production during LPS stimulation and LTB4 production during calcium ionophore stimulation, as indices of the expression of platelet COX-1, monocyte COX-2 and neutrophil 5-LO activities, respectively. This method has the advantage of taking into account the clinically relevant target cells and the variable degree of protein binding of NSAIDs (Blain et al., 2002). In previous in vivo studies in other species, tepoxalin has been shown to undergo rapid and extensive conversion to its carboxylic acid hydrolysis product (RWJ-20142). In those studies, plasma concentrations of RWJ-20142 were found to be substantially higher and more persistent than those of the parental drug. The PK findings in this study were in line with those observed in the other species, although the low numbers of animals used mean that the robustness of the PK parameters determined for tepoxalin is limited and further studies in more animals are required to confirm our findings. In horses, the RWJ-20142/tepoxalin Cmax ratio was about 12, similar to rabbits (Pollock et al., 2008). Studies in dogs (Homer et al., 2005) and humans (Depré et al., 1996; Waldman et al., 1996) reported values closer to five suggesting faster metabolism of tepoxalin in these species. When the AUC of RWJ-20142 obtained in this study was normalised to the orally administered dose of tepoxalin $(2756 \mathrm{ng} \mathrm{h} / \mathrm{mg})$, the values obtained were similar to those of fasting dogs (2747 $\mathrm{ng} \mathrm{h} / \mathrm{mg}$ ) (Homer et al., 2005), but higher than in chickens (1305 $\mathrm{ng} \mathrm{h} / \mathrm{mg}$ ) (De Boever et al., 2009) and rabbits (1807 ng $\mathrm{h} / \mathrm{mg}$ ) (Pollock et al., 2008). This suggests that, if the same dose of the drug per $\mathrm{kg}$ bodyweight (BW) is administered, RWJ-20142 will have longer plasma persistence in horses and dogs than in chickens and rabbits. Induced TXB2 concentrations measured in the present study were significantly higher when compared to values reported by Brideau et al. (2001) (256.3 $\pm 117.5 \mathrm{ng} / \mathrm{mL}$ and $83.9 \pm 22.1 \mathrm{ng} / \mathrm{mL}$ in fasting and fed horses, 
respectively, vs. $26 \pm 12 \mathrm{ng} / \mathrm{mL}$ ). The high concentration of vehicle (DMSO $0.4 \%$ ) used in the in vitro experimental design performed by Brideau and co-workers may account for this difference. In fact, it is well known that DMSO possesses anti-inflammatory activity, by inhibiting platelet aggregation induced by arachidonic acid in a concentration-dependent manner (Santos et al., 2003). After drug exposure, the production of TXB2 by platelets was significantly suppressed, but the production of PGE2 and LTB4 by LPS- and calciumstimulated white blood cells, respectively, was not significantly altered. So our results suggest that an oral dose of $10 \mathrm{mg} / \mathrm{kg}$ of tepoxalin can inhibit COX-1 activity in the horse, but not COX-2 and 5-LO, consistent with a significantly different COX inhibition ratio than that reported in other species. However, the large inter-individual variation of in PGE2 production, combined with the small number of animals $(n=3)$, may have resulted in a type II error (Warner, 2008). In the present study, inhibition of TXB2 production was detected for 2-72 $\mathrm{h}$ after drug administration, with peak inhibition reached between 2 and $48 \mathrm{~h}$. During this period of time, tepoxalin and its metabolite RWJ-20142 achieved maximal plasma levels, suggesting that both tepoxalin and its acid metabolite could be responsible for the COX-1 activity inhibition. The maximal inhibition of PGE2 occurred at $10 \mathrm{~h}$ contemporaneous with the Cmax of RWJ-20142, whereas that of LTB4 occurred at $2 \mathrm{~h}$ contemporaneously with the Cmax of tepoxalin. In the horse, the only previous report of the PD of tepoxalin in vitro (Caruso et al., 2009), confirmed its preferential inhibitory activity of COX-1 $($ IC50 $=0.0116 \mu \mathrm{M})$. In the same study, the inhibition of the COX-2 (IC50 $=0.0752 \mu \mathrm{M})$ was higher than that of 5 -LO $($ IC50 $=0.2233 \mu \mathrm{M})$, although in neither case was the inhibition significant. This finding of a preferential inhibition of COX-1 is consistent with the results of the present study (Table 2). However, in this study the inhibition of 5-LO tended to be higher than that of COX-2. This difference may be due to the in vivo metabolism of tepoxalin into its active metabolite RWJ-20142, which has a different PD profile from the parental compound. Comparing the maximum percentage of enzyme inhibitions with the cut-off values suggested by Giraudel et al. (2005), our results suggest that tepoxalin orally administered at a dose rate of $10 \mathrm{mg} / \mathrm{kg}$ would have weak antiinflammatory effects with a relatively high potential for adverse effects. Seventy-two hours after tepoxalin administration, COX-1 activity was still strongly inhibited, in both fasting and fed horses $(90.37 \pm 4.35 \%$ and $85.81 \pm 1.12 \%$, respectively), despite tepoxalin and RWJ20142 plasma concentrations both being under the LOQ. There was no such inhibition of COX-2 and 5-LO activities. The mechanism of a prolonged COX-1 activity inhibition for tepoxalin is not fully understood, but it could be related to its non-competitive mode of 
COX-1 inhibition, to the inhibition of COX-1 peroxidase (Munroe and Lau, 1995) or to possible covalent binding. Further investigation is required. It is unlikely, that tepoxalin acts like aspirin, (another non-competitive NSAID) as extensive dialysis of COX-1 enzyme after the drug administration can reverse the inhibitory effect of tepoxalin but not that of aspirin (Tam et al., 1995). In the dog, the influence of food has been reported to drastically increase both the bioavailability of tepoxalin and the production of RWJ-20142 (Homer et al., 2005). Diets that are rich in fats have been speculated to reduce the effect of the hepatic first-pass metabolism as a result of the preferential transport of the drug associated with lipoprotein into lymphatic vessels (Porter and Charman, 2001). In the horse, feeding a standard diet, which is low in fat, marginally influenced plasma concentrations of RWJ-20142. However the difference in $\mathrm{T} 1 / 2 \mathrm{kz}$ between groups is likely to be of negligible clinical relevance. Our horses were fed a high fibre diet, which may affect tepoxalin pharmacokinetics (Pollock et al., 2008) and could be the cause of the difference in plasma concentration of tepoxalin between the experimental groups. Feeding also seems to have influenced the basal level of PGE2, with marked differences between fed and fasting horses. These variations are consistent with early studies highlighting the increase of PGE2 after corn supplementation (Cargile et al., 2004; Hall et al., 2004). In horses the peak plasma level of tepoxalin was significantly lower than in dogs (0.53-1.08 $\mathrm{lg} / \mathrm{mL}$; Homer et al., 2005) and about half that in rabbits $(0.21 \mu \mathrm{g} / \mathrm{mL}$; Pollock et al., 2008), while the Cmax(s) of RWJ-20142 were consistent among all these species. Two different rate of metabolite formation were shown in both fed and fasted horses. The change in the slope of RWJ-20142 plasma concentration vs. time curves coincided with the beginning of the elimination phase of the parental drug. As soon as the parental drug concentration began to decrease, RWJ-20142 formation began to slowly increase. This could be due to rapid metabolism of tepoxalin in the gastrointestinal tract with subsequent absorption of the active metabolite and/or a higher rate of conversion of tepoxalin to RWJ-20142 than the rate of elimination, distribution and biotransformation of RWJ-20142. In the current study, as in chickens (De Boever et al., 2009), the presence of a time-dependent unknown peak was found in the chromatographic curves of plasma. It eluted between tepoxalin and the acid metabolite, in both fed and fasted horses. The unknown analyte represented approximately $10-15 \%$ in the peak area of the active metabolite and its maximal area was simultaneous with the Tmax of RWJ-20142 (10 h). This peak could potentially represent another active metabolite of tepoxalin. Further studies are needed to identify its molecular structure to further clarify the clinical effectiveness and safety of tepoxalin therapy. 
Conclusion In horses dosed orally with $10 \mathrm{mg} / \mathrm{kg}$ tepoxalin, the compound is present at very low levels in plasma because it is rapidly converted to its acid metabolite. At the tested dose rate, tepoxalin has both strong and long-lasting ex vivo inhibitory activity against COX-1. These effects seem mainly due to its main metabolite RWJ-20142. Tepoxalin and RWJ-20142 do not seem to possess either COX-2 or 5-LO inhibitory activity suggesting that, at a dose rate of $10 \mathrm{mg} / \mathrm{kg} \mathrm{BW}$, tepoxalin would have limited beneficial anti-inflammatory properties in horses, and that its long term use could be matter of concern.

\section{Conflict of interest statement}

None of the authors of this paper has a financial or personal relationship with other people or organizations that could inappropriately influence or bias the content of the paper.

\section{Acknowledgments}

Part of this paper will be communicated at the SIVE International congress. Authors thank professor C.C. Natalini for his comments/suggestions on the paper, Dr. J. Dorigo for technical assistance and Schering-Plough Co. for supplying the pure standard powders of tepoxalin, RWJ-20142 and RWJ-20294. This work was supported by the cooperation project Assistance and Qualification of the Animal Husbandry and Veterinary Medicine College of Xining - Qinghai Province (PRC) granted by The Italian Ministry of Foreign Affair as well as by Athenaeum funds. 


\section{REFERENCES}

Agnello, K.A., Reynolds, L.R., Budsberg, S.C., 2005. In vivo effects of tepoxalin, an inhibitor of cyclooxygenase and lipoxygenase, on prostanoid and leukotriene production in dogs with chronic osteoarthritis. American Journal of Veterinary Research 66, 966-972.

Anonymous, 2003. Zubrin technical monograph. Schering-Plough Animal Health, Union, NJ 07083-1982.

Argentieri, D.C., Ritchie, D.M., Ferro, M.P., Kirchner, T., Wachter, M.P., Anderson, D.W., Rosenthale, M.E., Capetola, R.J., 1994. Tepoxalin: a dual cyclooxygenase/5-lipoxogenase inhibitor of arachidonic acid metabolism with potent anti-inflammatory activity and a favorable gastrointestinal profile. Journal of Pharmacology and Experimental Therapeutics $271,1399-1408$.

Bertolini, A., Ottani, A., Sandrini, M., 2001. Dual acting anti-inflammatory drugs: a reappraisal. Pharmacological Research 44, 437-450.

Blain, H., Boileau, C., Lapicque, F., Nedelec, E., Loeuille, D., Guillaume, C., Gaucher, A., Jeandel, C., Netter, P., Jouzeau, J.Y., 2002. Limitation of the in vitro whole blood assay for predicting the COX selectivity of NSAIDs in clinical use. British Journal of Clinical Pharmacology 53, 255-265.

Brideau, C., Van Staden, C., Chan, C.C., 2001. In vitro effects of cyclooxygenase inhibitors in whole blood of horses, dogs, and cats. American Journal of Veterinary Research 62, 1755-1760.

Brooks, P.M., Day, R.O., 1991. Nonsteroidal anti-inflammatory drugs: differences and similarities. New England Journal Medicine 324, 1716-1725.

Cargile, J.L., Burrow, J.A., Kim, I., Cohen, N.D., Merritt, A.M., 2004. Effect of dietary corn oil supplementation on equine gastric fluid acid, sodium, and prostaglandin E2 content before and during pentagastrin infusion. Journal of Veterinary Internal Medicine 18, 545549.

Caruso, M., Zizzadoro, C., Crescenzo, G., Carofiglio, V., Ormas, P., Belloli, C., 2009. Inhibitory effects of tepoxalin on COX1/COX2 and 5-LOX in equine whole blood. Journal of Veterinary Pharmacology and Therapeutics 32, 108. Crooks, S.W., Stockley, R.A., 1998. Leukotriene B4. The International Journal of Biochemistry and Cell Biology 30, 173-178.

De Boever, S., Neirinckx, E., Baert, K., De Backer, P., Croubels, S., 2009. Pharmacokinetics of tepoxalin and its active metabolite in broiler chickens. Journal of Veterinary Pharmacology and Therapeutics 32, 97-100.

Depré, M., Van Hecken, A., Verbesselt, R., Verpooten, G.A., Arnout, J., Brunner, F., Jurgens, A., Pousset, V., Chow, A., Baldauf, C., Vermylen, J., De Broe, M., De Schepper, P.J., 1996. Biochemical activity, pharmacokinetics and tolerability of tepoxalin, a cyclooxygenase/5-lipoxygenase inhibitor, in man. International Journal of Clinical Pharmacological Research 16, 1-8. 
Derksen, F.J., Olszewski, M.A., Robinson, N.E., Berney, C., Hakala, J.E., Matson, C.J., Ruth, D.T., 1999. Aerosolized albuterol sulfate used as a bronchodilator in horses with recurrent airway obstruction. American Journal of Veterinary Research 60, 689-693.

Gabrielsson, J., Weiner, D., 2002. Pharmacokinetic and Pharmacodynamic Data Analysis: Concepts and Applications. Swedish Pharmaceutical Press, Stockholm, Sweden. pp. 114131.

Giorgi, M., Ye, G., Sgorbini, M., Corazza, M., 2011. Validation of a HPLC-FL method for the determination of tepoxalin and its major metabolite in horse plasma. Journal of Chromatographic Science 49, 79-83.

Giraudel, J.M., Toutain, P.L., Lees, P., 2005. Development of in vitro assays for the evaluation of cyclooxygenase inhibitors and predicting selectivity of nonsteroidal antiinflammatory drugs in cats. American Journal of Veterinary Research 66, 700-709.

Goldyne, M.E., 1984. Leukotrienes: clinical significance. Journal of the American Academy of Dermatology 10, 659-668.

Goodman, L., Torres, B., Punke, J., Reynolds, L., Speas, A., Ellis, A., Budsberg, S., 2009. Effects of firocoxib and tepoxalin on healing in a canine gastric mucosal injury model. Journal of Veterinary Internal Medicine 23, 56-62.

Goodrich, L.R., Nixon, A.J., 2006. Medical treatment of osteoarthritis in the horse - a review. The Veterinary Journal 171, 51-69.

Hall, J.A., Van Saun, R.J., Tornquist, S.J., Gradin, J.L., Pearson, E.G., Wander, R.C., 2004.

Effect of type of dietary polyunsaturated fatty acid supplement (corn oil or fish oil) on immune responses in healthy horses. Journal of Veterinary Internal Medicine 18, 880-886. Higgs, G.A., Moncada, S., 1985. Leukotrienes in disease. Implications for drug development. Drugs 30, 1-5.

Homer, L.M., Clarke, C.R., Weingarten, A.J., 2005. Effect of dietary fat on oral bioavailability of tepoxalin in dogs. Journal of Veterinary Pharmacology and Therapeutics 28, 287-291.

Knight, E.V., Kimball, J.P., Keenan, C.M., Smith, I.L., Wong, F.A., Barrett, D.S., Dempster, A.M., Lieuallen, W.G., Panigrahi, D., Powers, W.J., Szot, R.J., 1996. Preclinical toxicity evaluation of tepoxalin, a dual inhibitor of cyclooxygenase and 5-lipoxygenase, in Sprague-Dawley rats and beagle dogs. Fundamental and Applied Toxicology 33, 38-48.

Lascelles, B.D., McFarland, J.M., Swann, H., 2005. Guidelines for safe and effective use of NSAIDs in dogs. Veterinary Therapeutics 6, 237-251.

Lees, P., 2009. Autacoids and anti-inflammatory drugs. In: Riviere, J.E., Papich, J.E. (Eds.), Veterinary Pharmacology and Therapeutics. Wiley-Blackwell, Ames, IA, USA, pp. 457-492. 
Lees, P., Giraudel, J., Landoni, M.F., Toutain, P.L., 2004a. PK-PD integration and PK-PD modelling of nonsteroidal anti-inflammatory drugs: principles and applications in veterinary pharmacology. Journal of Veterinary Pharmacology and Therapeutics 27, 491-502.

Lees, P., Landoni, M.F., Giraudel, J., Toutain, P.L., 2004b. Pharmacodynamics and pharmacokinetics of nonsteroidal anti-inflammatory drugs in species of veterinary interest. Journal of Veterinary Pharmacology and Therapeutics 27, 479-490.

Los, M., Schenk, H., Hexel, K., Baeuerle, P.A., Droge, W., Schulze-Osthoff, K., 1995. IL- 2 gene expression and NF-kappa B activation through CD28 requires reactive oxygen production by 5-lipoxygenase. The EMBO Journal 14, 3731-3740.

Munroe, D.G., Lau, C.Y., 1995. Turning down the heat: new routes to inhibition of inflammatory signaling by prostaglandin H2 synthases. Chemical Biology 2, 343-350.

Pollock, C.G., Carpenter, J.W., Koch, D.E., Hunter, R.P., 2008. Single and multiple-dose pharmacokinetics of tepoxalin and its active metabolite after oral administration to rabbits (Oryctolagus cuniculus). Journal of Veterinary Pharmacology and Therapeutics 31, 171174.

Porter, C.J., Charman, W.N., 2001. Intestinal lymphatic drug transport: an update. Advanced Drug Delivery Reviews 50, 61-80.

Rainsford, K.D., 1987. The effects of 5-lipoxygenase inhibitors and leukotriene antagonists on the development of gastric lesions induced by nonsteroidal antiinflammatory drugs in mice. Agents and Actions 21, 316-319.

Rainsford, K.D., 1993. Leukotrienes in the pathogenesis of NSAID induced gastric and intestinal mucosal damage. Agents and Actions 39, 24-26.

Richardson, D.W., Loinaz, R., 2007. An evidence-based approach to selected joint therapies in horses. The Veterinary Clinics of North America Equine Practice 23, 443-460.

Santos, N.C., Figueira-Coelho, J., Martins-Silva, J., Saldanha, C., 2003. Multidisciplinary utilization of dimethyl sulfoxide: pharmacological, cellular, and molecular aspects. Biochemical Pharmacology 65, 1035-1041.

Stenson, W.F., Parker, C.W., 1984. Leukotrienes. Advances in Internal Medicine 30, 175199.

Tam, S.S., Lee, D.H., Wang, E.Y., Munroe, D.G., Lau, C.Y., 1995. Tepoxalin, a novel dual inhibitor of the prostaglandin- $\mathrm{H}$ synthase cyclooxygenase and peroxidase activities. The Journal of Biological Chemistry 270, 13948-13955.

Toutain, P.L., Bousquet-Mélou, A., 2004. Bioavailability and its assessment. Journal of Veterinary Pharmacology and Therapeutics 27, 455-466.

Waldman, S.A., Vitow, C., Osborne, B., Gillen, L., Argentieri, D.C., Wong, F.A., Smith, I.L., Chow, A.T., Misiti, J., Bjornsson, T.D., 1996. Pharmacokinetics and pharmacodynamics of tepoxalin after single oral dose administration to healthy volunteers. Journal of Clinical Pharmacology 36, 462-468. 
Wallace, J.L., McCafferty, D.M., Carter, L., McKnight, W., Argentieri, D., 1993. Tissueselective inhibition of prostaglandin synthesis in rat by tepoxalin: anti-inflammatory without gastropathy? Gastroenterology 105, 1630-1636.

Warner, R.M., 2008. Statistical power analysis. In: Warner, R.M. (Ed.), Applied Statistics. From Bivariate through Multivariate Techniques. Sage Publications, Los Angeles, USA, pp. 106-114.

Willburger, R.E., Wittenberg, R.H., Schmidt, K., Kleemeyer, K.S., Peskar, B.A., 1998. Antiinflammatory effect of tepoxalin: blood and synovial tissue studied in patients with knee arthrosis. Acta Orthopaedica Scandinavica 69, 295-300.

Zubrin (Tepoxalin) European Public assessment Report, European Agency for Evaluation of Medicinal Products, EPARs for authorised medicinal products for veterinary use, Rev. $11,02 / 10 / 08$. 
FIGURES AND TABLES

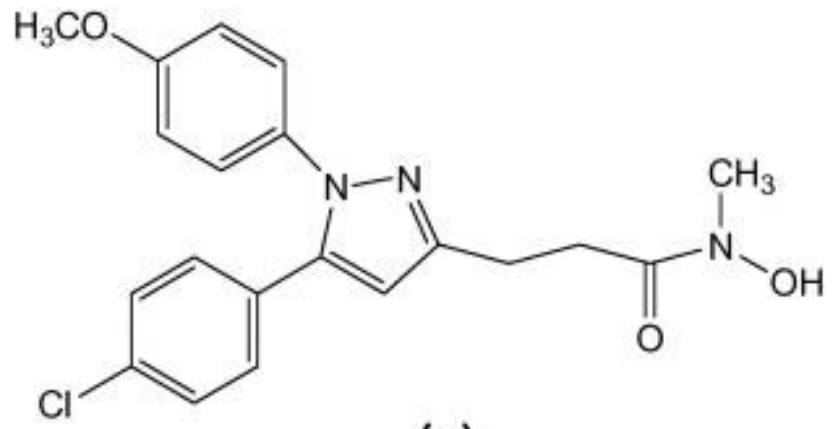

(a)<smiles>COc1ccc(-n2nc(CCC(=O)O)cc2-c2ccc(Cl)cc2)cc1</smiles>

(b)<smiles>COC(=O)CCc1cc(-c2ccc(Cl)cc2)n(-c2ccc(OC)cc2)n1</smiles>

Fig. 1. Molecular structure of (a) tepoxalin, (b) its active acid metabolite (RWJ-20142) and (c) internal standard (RWJ-20294). 


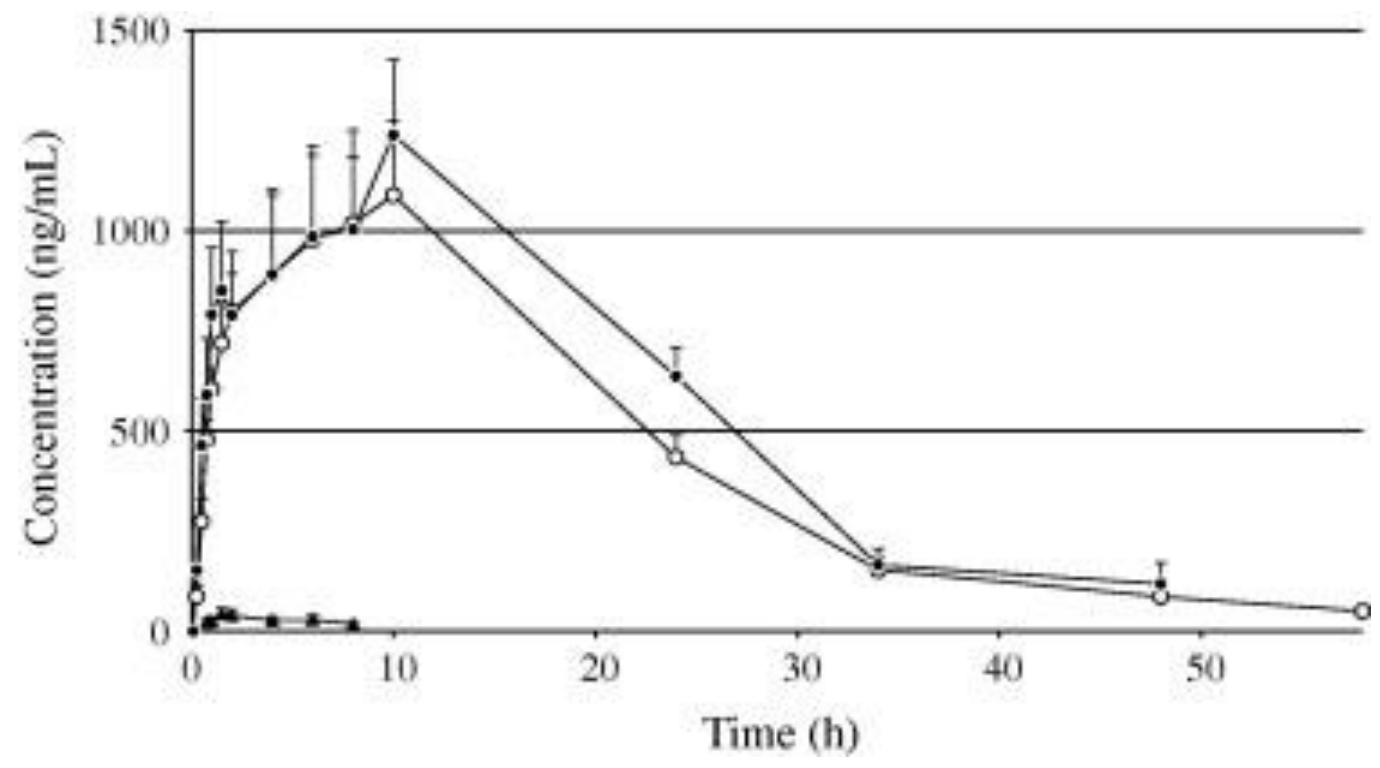

Fig. 2. Observed mean concentrations of tepoxalin in fasting horses $(\mathrm{N})$, and its active metabolite (RWJ-20142) in fasting (d) and fed horses (s), following single oral administration of $10 \mathrm{mg} / \mathrm{kg}$ tepoxalin $(n=6)$. Bars represent standard error of the mean. 

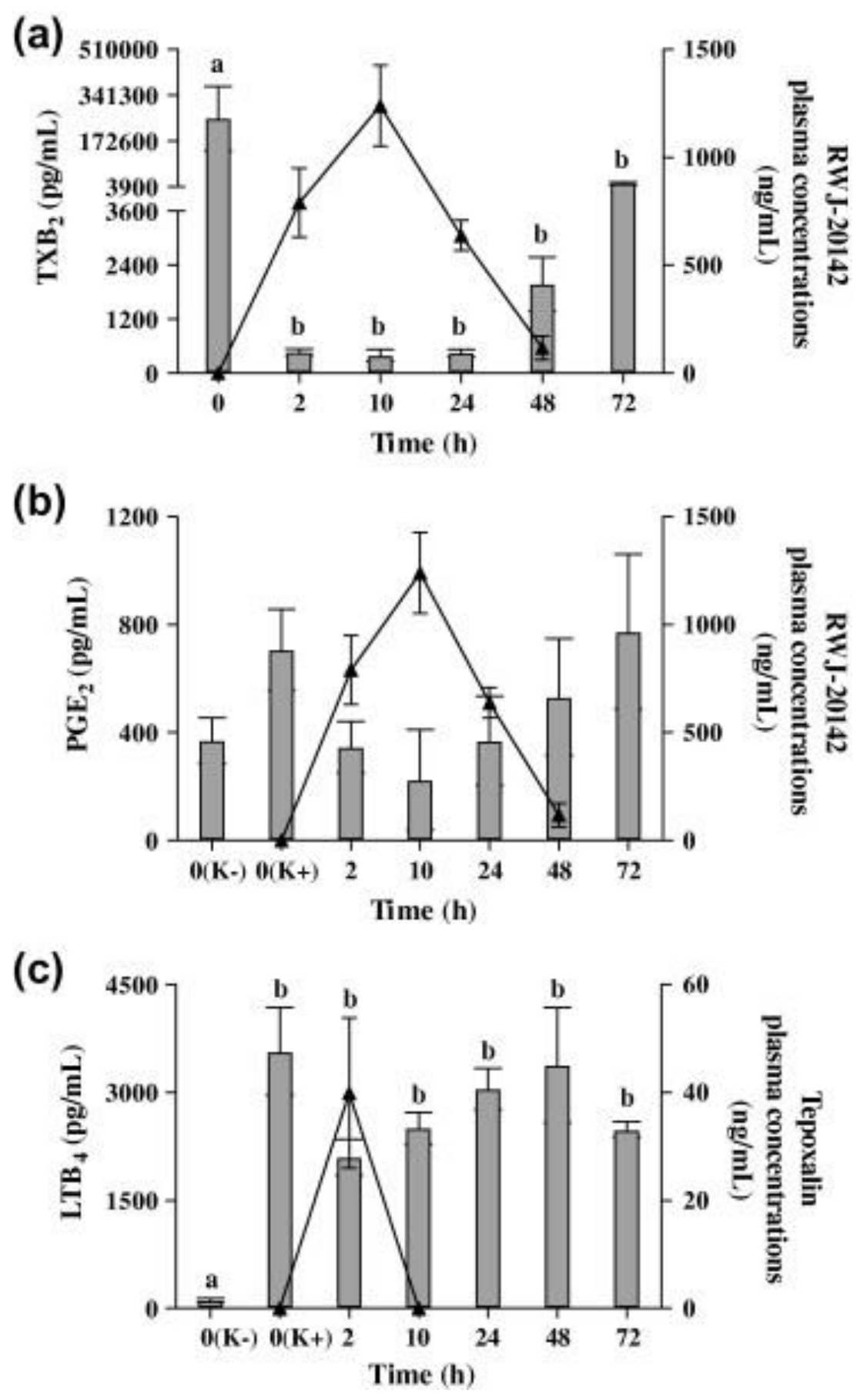

Fig. 3. Mean \pm SEM $(n=3)$ concentrations of thromboxane $B 2$ (TXB2; a), prostaglandin E2 (PGE2; b) and leukotriene B4 (LTB4; c) vs. RWJ-20142 or tepoxalin plasma concentrations in fasting equine whole blood before and after single oral administration of tepoxalin $(10 \mathrm{mg} / \mathrm{kg})$. Within time intervals, repeated-measures one-way ANOVA found values significantly different for TXB2 $(P<0.01 ; P<0.05)$ and for LTB4 $(P<0.001 ; P<$ 0.01). $\mathrm{K}-=$ negative control; $\mathrm{K}+=$ positive control. 

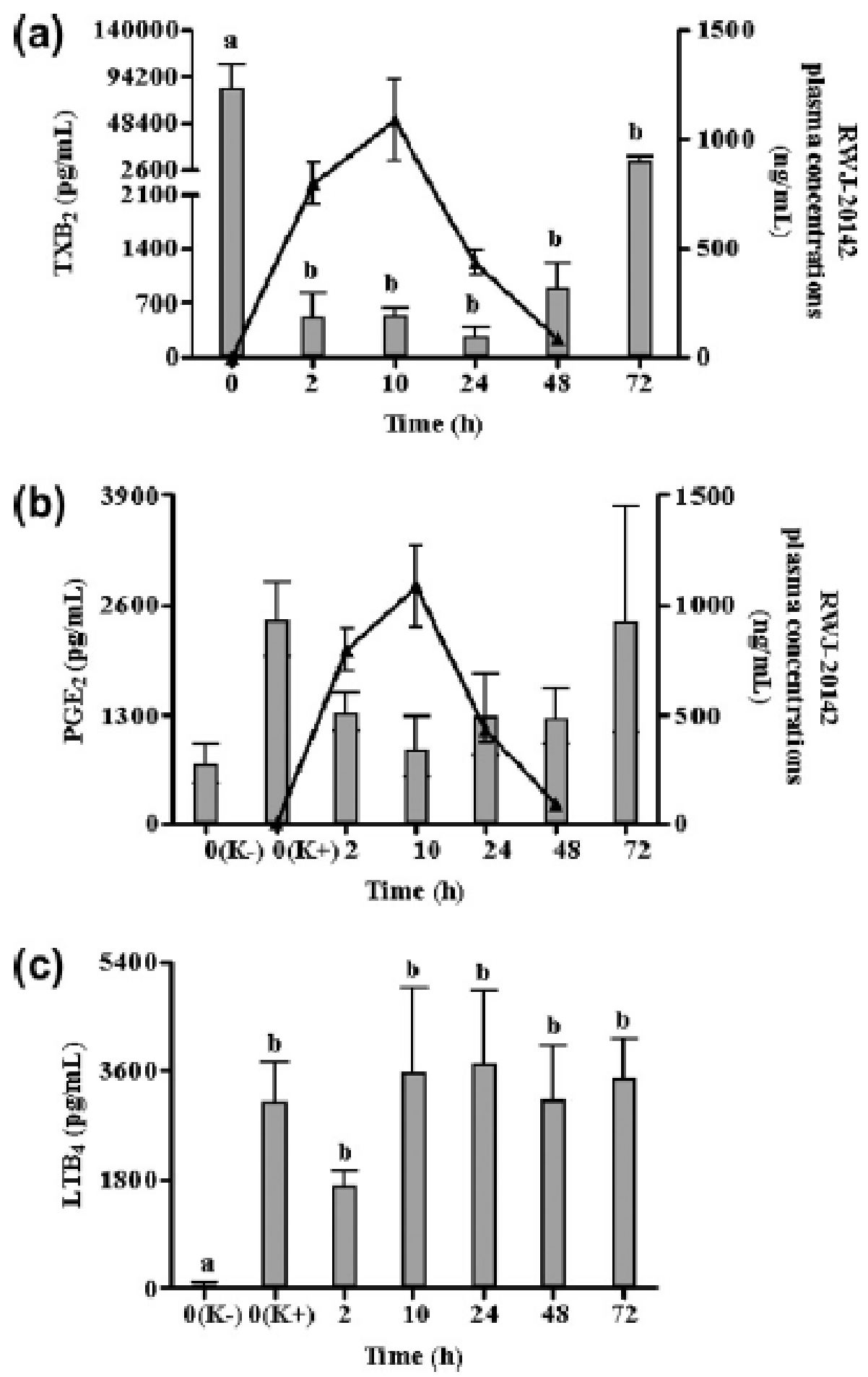

Fig. 4. Mean \pm SEM $(n=3)$ concentrations of thromboxane B2 (TXB2; a), prostaglandin E2 (PGE2; b) vs. RWJ-20142 plasma concentrations, and leukotriene B4 (LTB4; c) in fed equine whole blood before and after single oral administration of tepoxalin $(10 \mathrm{mg} / \mathrm{kg}$ ). Within time intervals, repeated-measures one-way ANOVA found values significantly different for TXB2 $(P<0.001)$ and for LTB4 $(P<0.01 ; P<0.05)$. $K-=$ negative control; $K_{+}$ $=$ positive control. 

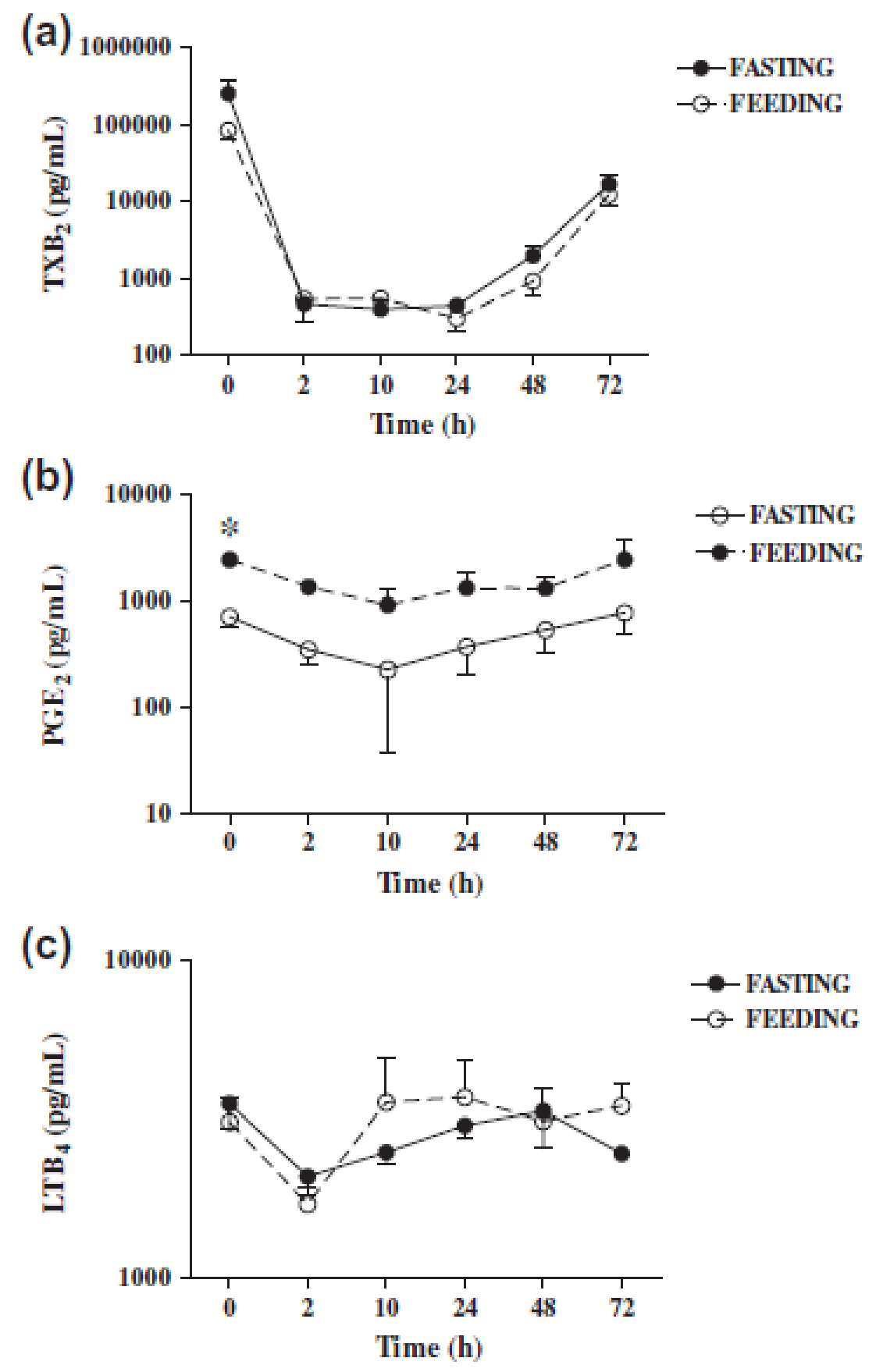

Fig. 5. Effect of feeding and fasting status on thromboxane B2 (TXB2; a), prostaglandin E2 (PGE2; b) and leukotriene B4 (LTB4; c) production in equine whole blood $(n=3)$ before and after oral single administration of tepoxalin $(10 \mathrm{mg} / \mathrm{kg})$. No interactions were seen between TXB2 and LTB4 levels and the feeding/fasting status $(P=$ not significant), whereas interactions were seen between PGE2 levels and the feeding/fasting status before tepoxalin administration $\left({ }^{*} P<0.05\right)$. Statistical analysis: two-way ANOVA. 


\begin{tabular}{|c|c|c|c|c|c|c|}
\hline \multirow[t]{3}{*}{ Parameter } & \multirow{2}{*}{\multicolumn{2}{|c|}{$\begin{array}{l}\text { Tepoxalin } \\
\text { Fasting }\end{array}$}} & \multicolumn{4}{|c|}{ RWJ-20142 } \\
\hline & & & \multicolumn{2}{|l|}{ Fasting } & \multicolumn{2}{|l|}{ Fed } \\
\hline & Mean & \pm SEM & Mean & \pm SEM & Mean & \pm SEM \\
\hline$r^{2}$ & $0.98^{1}$ & 0.01 & 0.93 & 0.03 & 0.98 & 0.01 \\
\hline$\lambda z(1 / \mathrm{h})$ & $0.40^{1}$ & 0.1 & 0.1 & 0.01 & 0.07 & 0.01 \\
\hline$T_{1 / 2} \lambda z(\mathrm{~h})$ & $2.78^{1}$ & 0.99 & $6.3^{\mathrm{a}}$ & 0.1 & $8.8^{\mathrm{a}}$ & 1.0 \\
\hline $\operatorname{Tmax}(\mathrm{h})$ & $1.5^{2}$ & 0.2 & 9.6 & 0.4 & 7.7 & 1.3 \\
\hline $\mathrm{Cmax}(\mathrm{ng} / \mathrm{mL})$ & $96.8^{2}$ & 55.0 & 1250 & 187 & 1197 & 198 \\
\hline $\mathrm{VzF}(\mathrm{mL} / \mathrm{kg})$ & 153.1 & 50.1 & Nd & $\mathrm{Nd}$ & $\mathrm{Nd}$ & $\mathrm{Nd}$ \\
\hline $\mathrm{CL}(\mathrm{mL} / \mathrm{h} / \mathrm{kg})$ & $50.1^{1}$ & 17.4 & $\mathrm{Nd}$ & $\mathrm{Nd}$ & $\mathrm{Nd}$ & $\mathrm{Nd}$ \\
\hline $\mathrm{AUC}_{\text {last }}(\mathrm{h} \mathrm{ng} / \mathrm{mL})$ & $190^{1}$ & 45.3 & 27,564 & 3307 & 24,553 & 3286 \\
\hline $\mathrm{AUMC}_{\text {last }}\left(\mathrm{h}^{2} \mathrm{ng} / \mathrm{mL}\right)$ & $640^{1}$ & 237.7 & 403,410 & 38,543 & 317,495 & 48,179 \\
\hline $\operatorname{MRT}_{\text {last }}(\mathrm{h})$ & $3.0^{1}$ & 0.6 & 15.2 & 1.0 & 15.1 & 1.5 \\
\hline
\end{tabular}

\section{Table 1}

Pharmacokinetic parameters of tepoxalin and RWJ-20142 following oral administrations of $10 \mathrm{mg} / \mathrm{kg}$ of tepoxalin in fasting and fed horses ( $\mathrm{n}=6$ except where indicated).

$\Upsilon 2$, correlation coefficient; $\lambda z$, terminal phase rate constant; $T 1 / 2 \lambda z$, terminal half-life; Tmax, time of peak; Cmax, peak plasma concentration; $\mathrm{VzF}$, volume of distribution based on the terminal phase; $\mathrm{CL}$, clearance of the terminal phase; AUClast, area under the plasma concentration-time curve; $\mathrm{AUMC}_{\text {last, }}$ area under the first moment curve; MRT last, mean resident time. Data originated from four ${ }^{1}$ and five ${ }^{2}$ horses. $\mathrm{Nd}=$ not detected.

a Value significantly different $(P<0.05)$ between fasting and fed groups. 


\begin{tabular}{|c|c|c|c|c|c|c|}
\hline \multirow[t]{3}{*}{ Time (h) } & \multicolumn{6}{|c|}{ Inhibition (\%) } \\
\hline & \multicolumn{2}{|l|}{$\mathrm{TXB}_{2}$} & \multicolumn{2}{|l|}{$\mathrm{PGE}_{2}$} & \multicolumn{2}{|l|}{$\mathrm{LTB}_{4}$} \\
\hline & Fasting & Fed & Fasting & Fed & Fasting & Fed \\
\hline 2 & $99.7 \pm 0.1^{\mathrm{a}}$ & $99.4 \pm 0.2^{\mathrm{a}}$ & $48.4 \pm 17.7$ & $49.4 \pm 3.6$ & $37.5 \pm 2.9^{\mathrm{a}}$ & $43.4 \pm 4.7$ \\
\hline 10 & $99.6 \pm 0.2^{\mathrm{a}}$ & $99.2 \pm 0.3^{\mathrm{a}}$ & $68.9 \pm 26.6$ & $65.1 \pm 8.0$ & $23.5 \pm 11.1^{\mathrm{ab}}$ & $-8.3 \pm 20.2$ \\
\hline 24 & $99.7 \pm 0.1^{\mathrm{a}}$ & $99.6 \pm 0.1^{\mathrm{a}}$ & $46.2 \pm 23.3$ & $48.9 \pm 11.3$ & $-3.1 \pm 9.4^{\mathrm{b}}$ & $-14.6 \pm 13.4$ \\
\hline 48 & $98.9 \pm 0.4^{\mathrm{a}}$ & $98.9 \pm 0.3^{\mathrm{a}}$ & $27.9 \pm 15.1$ & $45.8 \pm 14.3$ & $2.0 \pm 11.2^{\mathrm{ab}}$ & $1.8 \pm 8.8$ \\
\hline 72 & $90.4 \pm 4.3^{b}$ & $85.8 \pm 1.1^{\mathrm{b}}$ & $-5.7 \pm 28.0$ & $11.0 \pm 34.8$ & $11.3 \pm 1.1^{\mathrm{ab}}$ & $-15.4 \pm 18.2$ \\
\hline
\end{tabular}

\section{Table 2}

Mean \pm SEM $(n=3)$ of percentage (\%) inhibition of thromboxane B2 (TXB2), prostaglandin E2 (PGE2) and leukotriene B4 (LTB4) in fasting/fed equine whole blood before and after single oral administration of tepoxalin $(10 \mathrm{mg} / \mathrm{kg})$.

Repeated-measures one-way ANOVA revealed significant differences in \% inhibition of TXB2 of fasting ( ${ }^{a}$ vs. $\left.{ }^{b}, P<0.05\right)$ and fed horses ( ${ }^{a}$ vs. $\left.{ }^{b}, P<0.001\right)$, and LTB4 of fasting horses ( ${ }^{a}$ vs. $\left.{ }^{b}, P<0.05\right)$. No statistical differences were detected between fasting and fed groups. 